\title{
УСТРАНЕНИЕ КОНТРАКТУРЫ ЧЕЛЮСТЕЙ ПРИ ЗАМЕЩАЮЩЕМ ПРОТЕЗИРОВАНИИ ПОСТРЕЗЕКЦИОННЫХ ДЕФЕКТОВ ВЕРХНЕЙ ЧЕЛЮСТИ
}

\section{ELIMINATION OF JAW CONTRACTUAL WITH SUBSTITUTIONAL PROSTHETICS OF THE UPPER JAW DEFECTS}

\author{
V. Galonsky \\ N. Nurieva \\ V. Chernov \\ Yu. Kiparisov \\ A. Gradoboev
}

Summary. The article presents an analysis of the problem of the development of jaw contracture in general and with post-resection maxillary defects in particular. The reasons for the formation are indicated and the mechanisms of the development of this pathological condition are described in detail. The existing methods and methods of therapeutic measures for the elimination of contractures of the jaws of various origins are presented. The author describes the author's technique for eliminating jaw contraction in patients with maxillary post-resection defects, which is used as a special preparatory orthopedic measure before replacing prosthetics, which consists in the sequential use of a number of relaxation occlusal splints-splints with a gradual increase in the magnitude of de-occlusion of the dentition. A description of the principles and mechanisms of the therapeutic effect of the above technique is presented, its advantages are given in comparison with the known methods of therapeutic measures.

Keywords: contracture of the jaws, restriction of mouth opening, postresection maxillary defects, replacement prosthetics of jaw defects, splint splints.
Галонский Владислав Геннадьевич

Д.м.н., профессор, в.н.С., ФГБОУ ВО «Красноярский государственный медицинский университет имени профессора В.Ф. Войно-Ясенецкого gvg73@bk.ru

Нуриева Наталья Сергеевна Д.м.н., профессор, ФГБОУВО «Южно-уральский государственный медицинский университет»

natakipa@mail.ru

Чернов Владимир Николаевич

К.м.н., дочент, ФГБОУ ВО «Красноярский государственный медицинский университет имени профессора В.Ф. Войно-Ясенецкого»

chernovortstom@mail.ru

Кипарисов Юрий Сергеевич

К.м.н., ассистент, ФГБОУ ВО «Южно-уральский государственный медицинский университет

7407704@mail.ru

Градобоев Анатолий Владимирович

Врач-стоматолог, Стоматологическая клиника

«елиос»

solutiomortalis@gmail.com

Аннотация. В статье представлен анализ проблемы развития контрактуры челюстей в целом и при пострезекционных верхнечелюстных дефектах в частности. Указаны причины формирования и детально описаны механизмы развития данного патологического состояния. Приведены существующие методы и способы лечебных мероприятий по устранению контрактуры челюстей различного генеза. Описана авторская методика устранения контрактуры челюстей у больных с верхнечелюстными пострезекционными дефектами, применяемая в качестве специального подготовительного ортопедического мероприятия перед замещающим протезированием, заключающаяся в последовательном использовании ряда релаксационных окклюзионных шин-капп с постепенным увеличением величины дезокклюзии зубных рядов. Представлено описание принципов и механизмов лечебного воздействия вышеуказанной методики, приведены её преимущества, в сравнении с известными способами лечебных мероприятий.

Ключевые слова: контрактура челюстей, ограничение открывания рта, пострезекционные верхнечелюстные дефекты, замещающее протезирование дефектов челюстей, шины-каппы. 


\section{Актуальность}

O дним из основополагающих факторов успеха ортопедического стоматологического лечения является получение качественного оттиска опорных тканей протезного ложа. Особенностью получения оттисков при пострезекционном замещающем верхнечелюстном протезировании является необходимость точного проснятия послеоперационного дефекта по окружности и на всю глубину изъяна верхней челюсти, для обеспечения технических условий для формирования качественной обтурирующей части ортопедической конструкции с минимализированием возможности её вертикального смещения во время функциональной жевательной нагрузки, нивелируя негативный рычагообразный эффект, за счёт точности соответствия обтуратора пространственно-объёмному рельефу изъяна верхней челюсти. Существенным препятствием для получения качественных оттисков в данных клинических ситуациях, а в ряде случаев причиной полной невозможности выполнения данной манипуляции, может стать проблема контрактуры челюстей, часто сопровождающая данную патологию в послеоперационном периоде.

Контрактура челюстей - это не самостоятельное заболевание, а симптом, под которым понимают ограничение подвижности нижней челюсти в височно-нижнечелюстных суставах вплоть до полного сведения челюстей и неподвижности за счёт наличия внесуставной патологии. При этом различают три степени ограничения открывания рта, в зависимости от расстояния между режущими поверхностями верхних и нижних центральных резцов: I - амплитуда открывания рта слабо ограничена и возможна в пределах 30-40 мм, II - амплитуда открывания рта ограничена в пределах 10-15 мм, III - амплитуда открывания рта менее 10 мм.

Причинами контрактур челюстей могут быть: рубцовые изменения кожи, клетчатки, мышц, связок, костные спайки, воспалительные, опухолевые процессы и травмы околосуставных тканей. Систематизацию внесуставных нижнечелюстных контрактур можно представить следующим образом. По характеру течения различают: 1) нестойкие контрактуры, 2) стойкие контрактуры. По этиологии выделяют: 1) воспалительная контрактура жевательных мышц (тризм), 2) рефлекторная контрактура (тризм), 3) рубцовая контрактура, 4) механическая контрактура, 5) неврогенная контрактура (центрального генеза и периферического генеза), 6) агравационная контрактура.

К воспалительным контрактурам относятся патологические состояния, при которых в воспалительный процесс вовлекаются жевательные мышцы. Например, у лиц с околочелюстными абсцессами и флегмонами, затруднённым прорезыванием третьих моляров.

К рефлекторным контрактурам относятся патологические состояния, при которых у пациентов отсутствуют воспалительные изменения жевательных мышц, какие-либо другие препятствия, ограничивающие открывание рта, обусловленные изменениями со стороны височно-нижнечелюстных суставов. Ограничение движения нижней челюсти обусловлено болевой реакцией за счёт натяжения тканей при открывании рта. Классическим примером данного состояния может служить флегмоны щёчной области. Подобные ситуации могут возникать и при других воспалительных процессах и травматических повреждениях тканей окружающих нижнюю челюсть, за исключением процессов с вовлечением жевательных мышц.

Рубцовая контрактура может быть обусловлена рубцовым замещением ткани мышц, поднимающих нижнюю челюсть, а также тканей щёчной, околоушно-жевательной, зачелюстной, крыловидно-нижнечелюстной, окологлоточной, подвисочной и височной областей.

Механическая контрактура может возникать у больных с переломами скуло-глазнично-верхнечелюстного комплекса, опухолевыми и опухолеподобными процессами, инородными телами (пулевые, осколочные снаряды и др.), локализующимися в тканях окружающих ветвь или ветви нижней челюсти.

Неврогенная контрактура делится на две группы: центрального и периферического генеза. К первой группе относятся процессы, локализующиеся в области двигательных ядер тройничного нерва и воздействующие на них. Такие процессы, как столбняк, менингит, эпилепсия, опухоли, травмы головного мозга и другие, вызывают возбуждение в ядре, а из него уже идёт импульс на сокращение мышц. Ко второй группе относятся все остальные процессы, располагающиеся вне головного мозга и делящиеся на внутрисуставные и внесуставные, развивающиеся в тканях, окружающих нижнюю челюсть.

Агравационная контрактура - это редко частичное или чаще полное ограничение открывания рта при отсутствии органических изменений со стороны зубочелюстного аппарата (механических препятствий) и нервной системы, наступающее вследствие неосознанной симуляции.

Для устранения контрактуры челюстей предложены различные методы и способы лечения, имеющие большую или меньшую степень клинической эффективности в зависимости от вида патологии. В частности, методы 
медикаментозной терапии, сочетающие обезболивающий и миорелаксирующий эффекты фармакологических препаратов, используемые более в практике неврологии [1], курсы физиотерапии и ЛФК [2], постизометрическая релаксация мускулатуры челюстно-лицевой области с использованием приёмов мануальной терапии [3], хирургические способы, в большей степени направленные на устранение механических препятствий нижнечелюстным движениям и рубцово изменённых тканей $[4,5]$. Наиболее широкое применение в практике челюстно-лицевой ортопедии для решения данной проблемы нашли методы активной механотерапии с использованием специальных устройств - роторасширителей различных конструкций, основанных на принципе действия рычага, или мануального пальцевого давления, осуществляемые методическими повторными многократными сеансами. Данный принцип терапии в большей степени направлен на устранение физиологического компонента патогенеза поражения жевательной мускулатуры, на медицинском сленге именуемом «разработкой мышц» $[6,7]$. Тем не менее, практически все конструкции роторасширителей обладают одним широко распространённым недостатком - это грубое силовое воздействие на опорные зубы. Подобная хроническая механическая травма может привести к переломам опорных зубов, их вывихам или повреждению пародонта. Самостоятельное пальцевое давление пациентом для достижения стойкого роторасширяющего эффекта, приближающегося к физиологической норме, обладает клинически маловероятной эффективностью.

Таким образом, анализ научной литературы показал, что существующие различные методы и способы устранения контрактуры челюстей, теоретически направленные на решение данной проблемы, мало применимы в челюстно-лицевой ортопедии у больных с пострезекционными верхнечелюстными дефектами и не получили практического клинического подтверждения свой эффективности. В данной связи, в условиях стоматологической практики, данная категория больных на значительный период времени остаётся без оказания реабилитационных ортопедических стоматологических мероприятий по техническим причинам невозможности их выполнения. Это ведёт в свою очередь к формированию ряда специфических осложнений таких, как изменение пространственно-объёмных размеров послеоперационной полости («её сморщивание») и стойкое нарушение конфигурации лица за счёт западения мягких тканей на стороне изъяна, как результат рубцовой деформации. Исправить или эффективно скорректировать данные морфологические и эстетические недостатки в последующем с использованием протезно-ортопедических конструкций и в ряде случаев хирургических методов лечения практически невозможно.

\section{Шель работы}

Повышение качественных характеристик замещающего протезирования пострезекционых дефектов верхней челюсти, путём эффективного предварительного устранения контрактур челюстей.

Многолетний содружественный опыт совместной межвузовской работы профильных кафедр стоматологических факультетов Красноярского государственного медицинского университета им. проф. В.Ф. Войно-Ясенецкого» и Южно-уральского государственного медицинского университета по изучаемой проблеме в ортопедической стоматологической реабилитации данной категории больных, наблюдению ближайших и отдаленных результатов лечения позволяет заключить, что формирование контрактуры челюстей у больных с верхнечелюстными пострезекционными дефектами имеет особенности, определяемые взаимодействием ряда патогенетически взаимосвязанных и взаимообусловленных факторов - операционная травма, рубцовая деформация, повреждение лучистой энергией после лучевой терапии тканей мышц челюстно-лицевой области и элементов височно-нижнечелюстного сустава, отсутствие функциональной нагрузки зубочелюстного аппарата, болевой синдром и др. Как результат проявления последствий лучевой терапии являются прогрессирующий каскад микроциркуляторных нарушений за счёт облитерирующей ангиопатии, явлений фиброзного дегенерирования в тканях жевательных мышц, последующего гиалиноза, вплоть до развития очагового кальциноза (оссифицирующего миозита), а также поражения структурных элементов височно-нижнечелюстного сустава. Функциональный паралич жевательных мышц и, как следствие, значительная и стойкая их атрофия, усугубляются наличием элементов агравационного симулирования на фоне выраженного болевого синдрома. То есть, иными словами, можно сказать, что контрактура челюстей у данной категории больных по своей сути и содержанию включает в себя отдельные компоненты нескольких из вышеперечисленных в систематике, взаимосвязанных между собой и отягощающих друг друга, формируя патогенетический замкнутый круг развития патологии.

Согласно нашему многолетнему клиническому опыту, наиболее эффективным методом устранения контрактур челюстей в данных клинических ситуациях является наша авторская методика, заключающаяся в последовательном использование ряда сменяемых друг друга релаксационных окклюзионных шин-капп с постепенным увеличением высоты дизокклюзии с шагом до 5 мм, изготовленных из акриловой пластмассы непрямым методом. Рекомендуемое время использования шин-капп пациенту составляет 24 часа в сутки, 


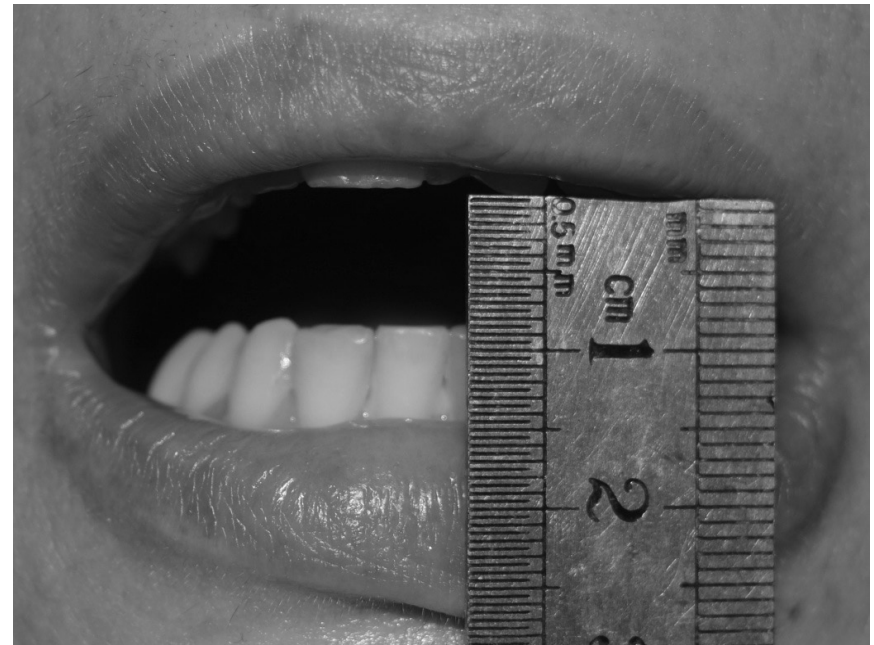

Рис. 1. Уровень ограничения открывания полости рта больной С. до начала ортопедического лечения.
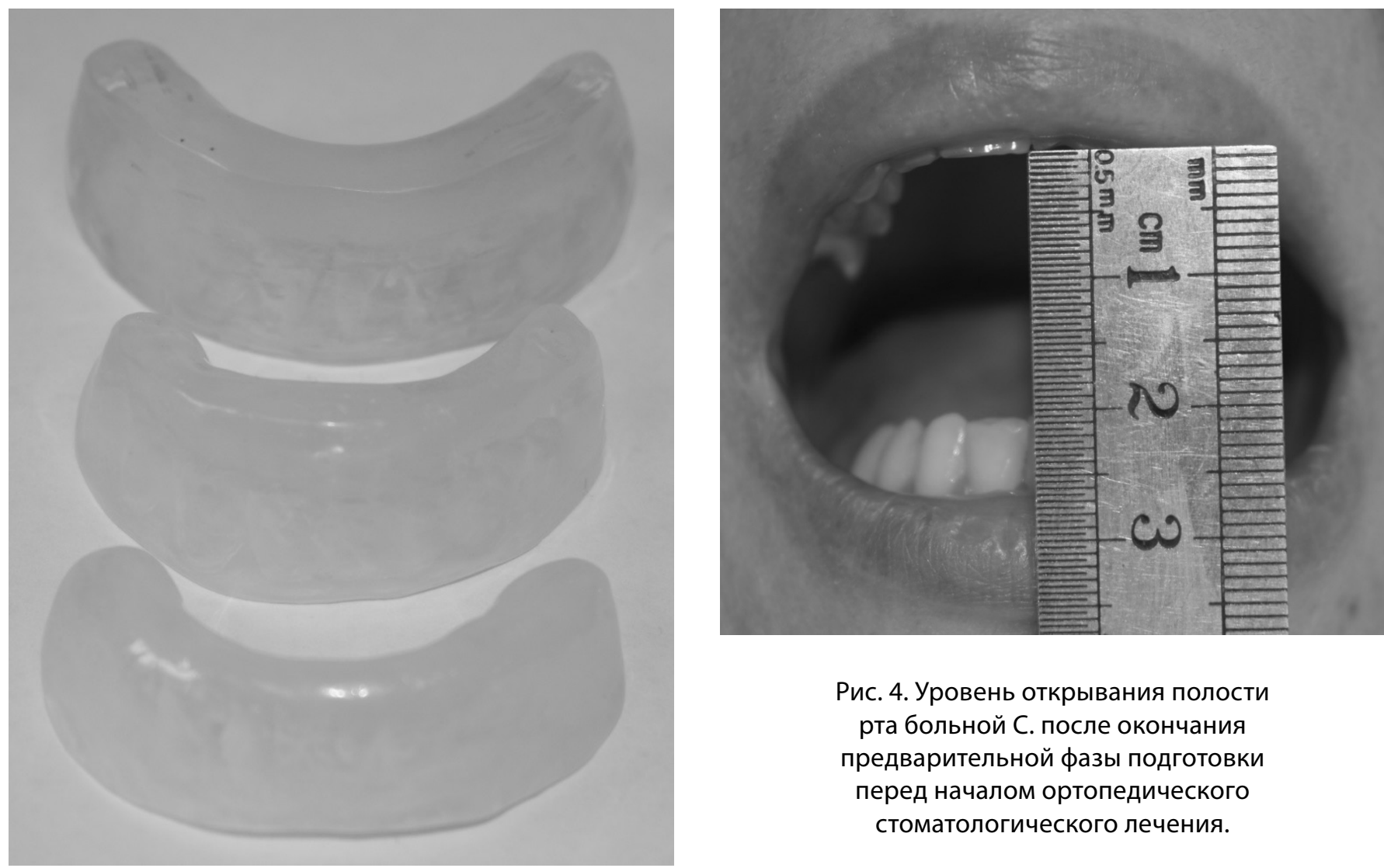

Рис. 4. Уровень открывания полости рта больной С. после окончания предварительной фазы подготовки перед началом ортопедического стоматологического лечения.
Рис. 2. Релаксационная окклюзионная шина-каппа в полости рта больной С. в положение закрытого рта.

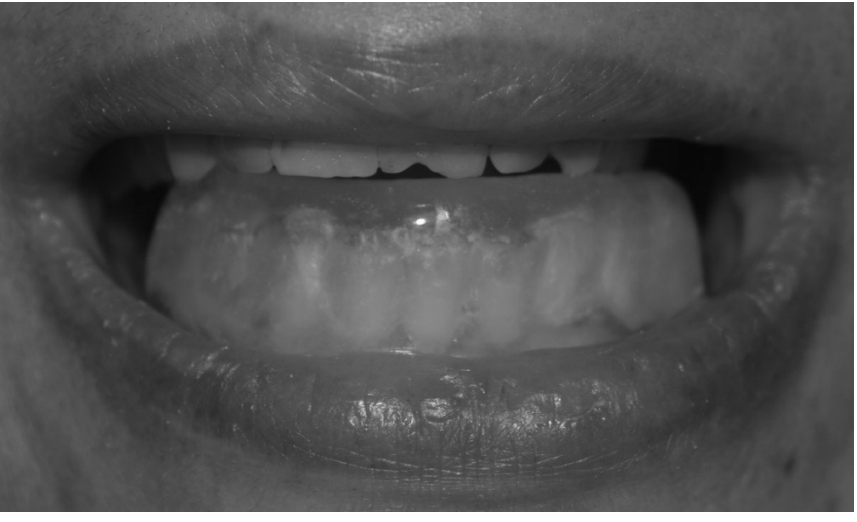

Рис. 3. Линейка динамически заменяемых релаксационных окклюзионных шин-капп больной С. для устранения контрактуры челюстей. 


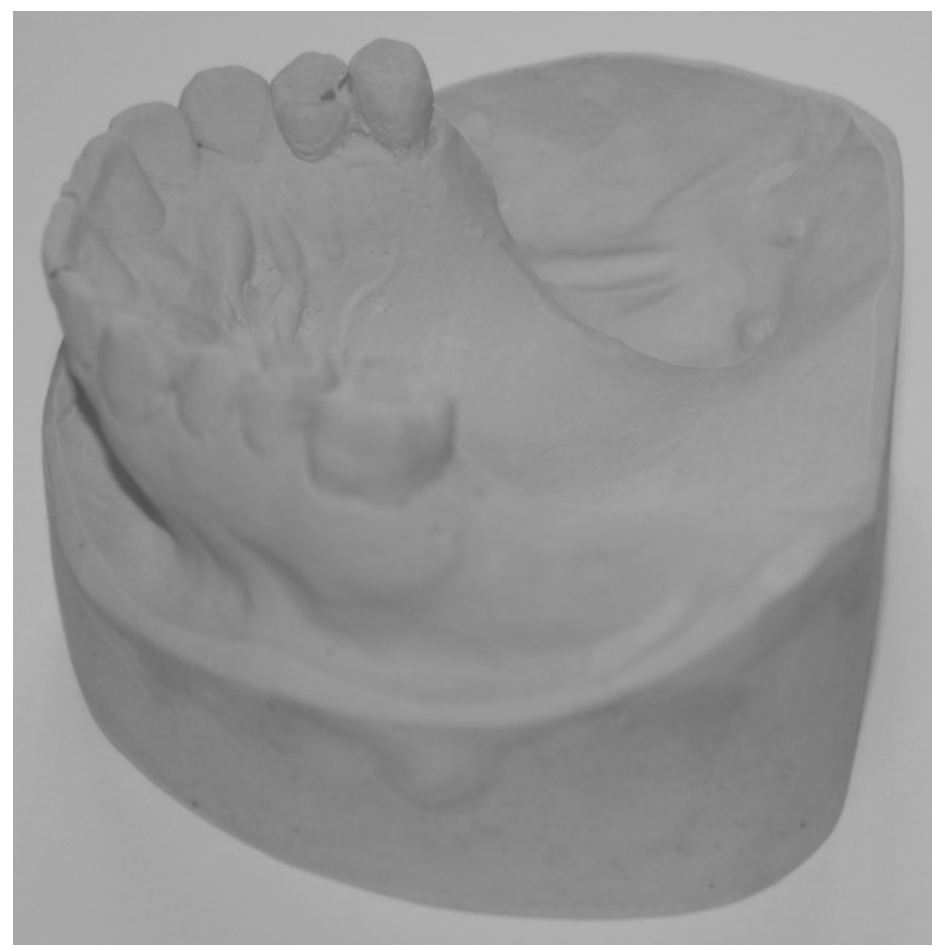

Рис. 5. Рабочая гипсовая модель пострезекционного верхнечелюстного дефекта больной С., полученная по верхнечелюстному оттиску по окончании устранения контрактуры челюстей.

за исключением периодов приёма пищи. Шаг увеличения дезокклюзии составляет от 14 до 28 суток в зависимости от индивидуального течения адаптационного периода в конкретной клинической ситуации. Средняя продолжительность курса, позволяющего планомерно и постепенно обеспечить полную релаксацию, растяжение и депрограмирование жевательных мышц до уровня физиологической нормы с устранением ограничения открывания рта и обеспечения технической возможности получения качественного оттиска, по нашим клиническим наблюдениям, в среднем составляет временной период до 3 мес.

В качестве иллюстрации метода приводим клиническое наблюдение. Больная C. 40 лет. DS: C-r верхней челюсти слева (C41.0), состояние после комбинированного лечения, пострезекционный дефект альвеолярного отростка и тела левой верхнечелюстной кости в проекции отсутствующих зубов 2.6, 2.7, 2.8 (М95.2), контрактура челюстей III степени (К07.6, М24.5), частичная вторичная верхнечелюстная адентия I класса по Кеннеди (К08.1). Устранение нижнечелюстной контрактуры выполнено с использованием трёх последовательно сменяемых друг друга релаксационных окклюзионных шин-капп с постепенным увеличением величины дезокклюзии в течение трёх месяцев (рис. 1-4). В результате лечения величину свободного открывания рта удалось увеличить с 8 мм (рис. 1) до до 21 мм (рис. 4), с обеспечением технической возможности свободного получения качественного оттиска верхнечелюстного изъяна по которому изготовлена рабочая гипсовая модель (рис. 5) и в последующем верхнечелюстной протез обтуратор.

\section{Зак^ючение}

Наш многолетний практический опыт решения проблемы контрактуры челюстей у больных с верхнечелюстными пострезекционными дефектами путём последовательного использования сменяемых друг друга релаксационных окклюзионных шин-капп с постепенным увеличением высоты дизокклюзии показал высокую клиническую эффективность. Функционально-физиологический метод лечебного воздействия на различные звенья патогенеза развития контрактуры челюстей у данной категории больных позволяет разобщить замкнутый патогенетический круг её развития и добиться планомерной и постепенной релаксации, растяжения и депрограмирования жевательных мышц, а также адекватного функционирования элементов височно-нижнечелюстных суставов до приблизительного уровня физиологической нормы с устранением ограничения открывания рта. Вынужденная физическая нагрузка, оказывая действие на течение патологического процесса, усиливает крово- и лимфообращение в зоне повреждения, при соответствующей лечебной 
программе систематического применения релаксационных окклюзионных шин-капп, вызывающих принудительную нагрузку на повреждённую мышечную ткань и усиленное лимфо и кровообращение, стимулирует рассасывание продуктов воспаления в очаге поражения, что способствует улучшению окислительно-восстановительных процессов и ускорению регенеративной способности повреждённой ткани с учётом функционального компонента. Предложенный метод устранения контрактуры челюстей у больных с верхнечелюстными пострезекционными дефектами прост В применении, не требует специального дорогостоя- щего оборудования и расходных материалов, а также специальной подготовки врачебных и зуботехнических кадров, обладая при этом элементом экономической целесообразности на фоне высокой клинической эффективности. В данной связи разработанный метод рекомендуется для широкого клинического применения.

\section{КонфАикт интересов}

Авторы декларируют отсутствие явных и потенциальных конфликтов интересов, связанных с публикацией настоящей статьи.

\section{ЛИТЕРАТУРА}

1. Рабиева, М.М. Применение препарата катадолон при лечении невропатии лицевого нерва, осложненной контрактурой мимических мышц с патологическими синкенезиями / М.М. Рабиева, С.Г. Рустамов, 0.Ю. Гончарова // Научно-практический журнал ТИППМК. — 2013.— № 2.— С. 113-114.

2. Филиппова, Л.А. Роль лечебной физкультуры при выраженной воспалительной контрактуре челюстей / Л.А. Филиппова, А.А. Филиппова // Главный врач Юга России. - 2017. - № 55.—C. 21-22.

3. Опыт лечения больных с контрактурами мимических мышц приёмами мануальной терапии / А.Н. Емец, С.А. Дудариков, И.О. Плотникова [и др.] // В книге: Клиническая и патоморфологическая диагностика редко встречающихся повреждений и заболеваний. Случаи из практики.- Благовещенск, 2015.- С. 48-50.

4. Поляков, А.П. Хирургические аспекты устранения внесуставных и внутрисуставных контрактур височно-нижнечелюстного сустава у пациентов с опухолями головы и шеи / А.П. Поляков // Злокачественные опухоли. — 2016. — № 4(21). — C. 315.

5. Шалумов, А.З. Лечение контрактуры височно-нижнечелюстного сустава, развившейся вследствие сочетанной черепно-лицевой травмы / А.3. Шалумов, А.Э. Талыпов // Нейрохирургия.— 2015.— № 1.—C. 87-89.

6. К Климашин, Ю.И. Эффективный атравматичный способ механотерапии с эффектом роторасширения / Ю.И. Климашин, А.А. Горин // Медицинский алфавит. - 2012. - Т. 4., № 19.- С. 18-19.

7. Ковалёва, А.С. Ортопедические методы лечения при контрактурах и микростомии / А.С. Ковалёва, Э.Ф. Амоян, С.А. Хакуй // Международный журнал прикладных и фундаментальных исследований.— 2016.— № 11(4).—C. 688-689.

○ Галонский Владислав Геннадьевич ( gvg73@bk.ru ), Нуриева Наталья Сергеевна ( natakipa@mail.ru ),

Чернов Владимир Николаевич ( chernovortstom@mail.ru ), Кипарисов Юрий Сергеевич ( 7407704@mail.ru ),

Градобоев Анатолий Владимирович ( solutiomortalis@gmail.com ).

Журнал «Современная наука: актуальные проблемы теории и практики» 